\title{
Inference as Consciousness of Necessity
}

\author{
Eric Marcus \\ Auburn University \\ (forthcoming in Analytic Philosophy)
}

Consider the following three claims. (i) There are no truths of the form 'p and $\sim$ p'. (ii) No one holds a belief of the form 'p and p'. (iii) No one holds any pairs of beliefs of the form $\{p, \sim p\}$. Irad Kimhi has recently argued, in effect, that each of these claims holds and holds with metaphysical necessity. Furthermore, he maintains that they are ultimately not distinct claims at all, but the same claim formulated in different ways. ${ }^{1}$ I find his argument suggestive, if not entirely transparent. I do think there is at least an important kernel of truth even in (iii), and that (i) ultimately explains what's right about the other two. Consciousness of an impossibility makes belief in the obtaining of the corresponding state of affairs an impossibility. Interestingly, an appreciation of this fact brings into view a novel conception of inference, according to which it consists in the consciousness of necessity. This essay outlines and defends this position. A central element of the defense is that it reveals how reasoners satisfy what Paul Boghossian calls the Taking Condition and do so without engendering regress.

\section{Two Regresses}

\footnotetext{
${ }^{1}$ Kimhi 2018. He would not put his view this way, but to explain the discrepancy would take us too far afield.
} 
I begin with a brief summary of Lewis Carroll's "What the Tortoise Said to Achilles”. I do not believe its lesson is well-understood. ${ }^{2}$ The tortoise draws Achilles's attention to a pair of obviously true premises from which a conclusion obviously logically follows. The tortoise then challenges Achilles to "force" him "logically" to accept the conclusion. 3 The tortoise does not consider himself forced yet, since, as Achilles must acknowledge, it is possible for someone to believe the premises but fail to believe that they entail the conclusion; i.e., someone might fail to believe the hypothetical statement in which the premises are conjoined as the antecedent and the conclusion is the consequent. Achilles attempts to overcome this problem by asking the tortoise to accept the hypothetical statement as an additional premise. The tortoise is happy to oblige; and Achilles thinks his work is done. But no. It is possible, after all, for someone to accept all three premises yet fail to draw the conclusion. The tortoise will therefore not consider himself forced to draw it. Achilles insists that he must, since the three premises obviously logically entail the conclusion. But the tortoise counters that that is a further premise which itself must then be added to the argument if the premises really are to force him to accept the conclusion. And so on.

Carroll's tale draws us towards the idea that there is a psychological gap between accepting the premises of a simple inference and accepting the conclusion. Once we attempt to fill the gap with an additional thought, the regress is off and running; the addition is never enough. Yet to add no thought ensures that the conclusion will either never be reached or that it will be reached blindly, i.e., not, as we might put it, under the

\footnotetext{
${ }^{2}$ An exception is Stroud 1979.

3 Carroll 1895, 692
} 
subject's own cognitive steam. Either way, the subject does not reach the conclusion by way of inference. Inference thus seems impossible. To put it another way: If the most that one who infers can apprehend is just what the tortoise apprehends (or in any case pretends to apprehend), then inferring is something external to apprehension. 4 We can formulate the difficulty in terms of Boghossian's

(Taking Condition): Inferring necessarily involves the thinker taking his premises to support his conclusion and drawing his conclusion because of that fact. 5

The thought behind the Taking Condition is that the inferential transition from premisebeliefs to conclusion-belief necessarily occurs as a result of my appreciation of the support that the premises lend to the conclusion. I am moved to accept the conclusion in virtue of appreciating what we can call this first-level support-fact. However the idea of appreciation is ultimately to be explained -whether in terms of belief, intuition or something else-it will have to include an awareness of this fact. Furthermore, my being moved by an awareness of the first-level support-fact is itself not a purely blind, mechanical sort of being-moved, but a being-moved that transpires in part in virtue of

4 A practical analogue to this difficulty is raised by akrasia. If the most that the ordinary agent can apprehend in the way of knowledge of what is to be done is just what the akratic apprehends, then responsiveness to such knowledge must be something external to apprehension. The action itself will thus appear to be something outside the space of reasons.

5 Boghossian 2014, 5 . 
my endorsement. I am moved by the first-level support-fact because I appreciate that being so moved is itself epistemically supportable. And that appreciation encompasses an awareness of a second-level support-fact. I must appreciate the support that the combination of the original premises and the first-level support fact lend to the conclusion. And we are not blindly moved by an awareness of the second-level support fact. And so forth. In this way, the Taking Condition seems to require reaching out to ever more propositions in the light of whose truth the conclusion is to be drawn in order to count as an inference. And to allow at any point that one does not need this further help would be simply to abandon what makes the Taking Condition seem plausible to begin with. So, again, it is impossible to reach the conclusion via inference. ${ }^{6}$

It is worth emphasizing that nowhere in the foregoing statement of the problem do I rely either explicitly or implicitly on classifying the relevant appreciations as new premises. All that is required to generate the puzzle is the idea that the connection between premise and conclusion must be appreciated. This alone generates a vicious regress, since no matter how much we appreciate, more will be necessary to reach the conclusion.

Carroll's regress presents as impossible believing a proposition in light of its following from others that one accepts. I now turn to a closely related regress, one that

${ }^{6}$ The regress Boghossian discusses in his 2003 only gets half of Carroll's point. Carroll's point concerns how a grasp of the justification can explain the adoption of the belief, whereas Boghossian 2003 concerns only justification-he explicitly puts 'taking' aside (see his note 2). Still, I take the solution to Carroll's regress offered here to suggest a strategy for dealing with this problem as well. I discuss it in Marcus, ms. 
presents as impossible disbelieving a proposition in light of its inconsistency with others one accepts.

Suppose I believe that $\mathrm{p}$-an ordinary simple, proposition-and that I have amazing evidence that $\mathrm{p}$, am supremely and justifiably confident that $\mathrm{p}$, etc. But suppose you, who are an expert on all things p-ish, tell me that I should also adopt the belief that $\sim$ p. You do not suggest that I give up my belief that $\mathrm{p}$, just that I accept $\sim \mathrm{p}$ as a further belief. Appreciating that they are incompatible, I reject your suggestion out of hand. How should we understand the role played by my appreciation of their incompatibility in the rejection of the belief that $\sim$ p? Plainly, it plays some role: I reject $\sim \mathrm{p}$ in part because I take it to be incompatible with $\mathrm{p}$, which I know to be true. We must, it seems, understand the rejection as involving an awareness of the fact that $\sim(p$ and $\sim$ p). Without some such awareness, my rejection of your suggestion would be blind. By the same rationale, however, I must also appreciate that $\sim \mathrm{p}$ is incompatible with the conjunction of $\mathrm{p}$ and $\sim(\mathrm{p}$ and $\sim \mathrm{p})$. That is, if part of what it is to reject $\sim \mathrm{p}$ because it is incompatible with $\mathrm{p}$ involves an awareness that $\sim(\mathrm{p}$ and $\sim \mathrm{p})$, then it must also involve an appreciation of the fact that $\mathrm{p}, \sim \mathrm{p}$ and $\sim(\mathrm{p}$ and $\sim \mathrm{p})$ are incompatible. But this too presumably involves a further appreciation. And a vicious regress is off and running. As in the case of Carroll's, any attempt to shrug off the requirement of higherlevel appreciation will undermine the rationale for taking it to be a requirement at the initial stage.

Note that it does not matter-or in any case it does not seem to matter-whether the appreciation of the clash between $\mathrm{p}$ and $\sim \mathrm{p}$ is thought of as itself a belief or something else. What matters is that to credit someone with the relevant appreciation of the first-level incompatibility, we must also credit them with an appreciation of the 
second-level incompatibility (i.e., between $\mathrm{p}, \sim \mathrm{p}$ and $\sim(\mathrm{p}$ and $\sim \mathrm{p})$ ). Were it stipulated that a subject lacked the latter appreciation, we could no longer credit them with the former appreciation. And so it seems we could never appreciate enough to reject a proposition simply in virtue of its incompatibility with a proposition we know to be true.

What emerges from our transposition of Carroll's regress into this new key?

There is, I will argue, an element present in both phenomena that will ultimately lead us to an escape from regress. In each case, there is a kind of metaphysical necessity operative-a can't in the case of incompatibles, a must in the case of inference - that is rooted in the subject's understanding of a logical necessity. But the point is easier to see in the former case, so I begin with my solution to the variant.

\section{What I Can't Believe}

Statements of the form "p and not-p" are deeply puzzling. They are not puzzling because we find the expressed attitude rationally deficient. Rather, we have no idea what attitude towards $\mathrm{p}$ to ascribe the speaker. Such statements are-at least when we attempt to interpret them as ordinary conjunctions-unintelligible. (Perhaps there are some highly unusual exceptions, e.g., where $\mathrm{p}$ is related to one of the paradoxes of selfreference. I put these to one side here.)

Why should we have no idea what state of mind the asserter of "p and $\sim p$ " purports to express? Here is a simple if initially unpromising answer: It is impossible and not merely rationally deficient to believe a contradiction. The answer seems to be unpromising for at least this reason: the assertion of a complex proposition that contains a contradiction in some well-disguised form is intelligible. For someone might 
mistakenly take it to be true and assert it. This suggests that what is genuinely impossible is that someone believe a contradiction and also believe that it is a contradiction. Believing it to be a contradiction, and hence false, one disbelieves it. But then the impossibility would be: believing what one takes to be false; and not: believing a contradiction.

Yet: if a thinker fully understands a contradiction, then she knows that it is necessarily false, and so cannot believe it. That is, to credit someone with the conceptual wherewithal to grasp fully the meaning of a contradictory statement is at the same time to attribute to her knowledge that the statement cannot be true. With this in mind, let us consider a proposition that has the form $\mathrm{p} \& \sim \mathrm{p}$, say: "it's raining and it's not raining." Someone who fails to understand that this is a contradiction does not qualify as understanding it sufficiently well to genuinely believe it. I don't have a general test for when someone understands a proposition sufficiently well to qualify as believing it, but I will assume here (a) that there is such a thing as what I will call a qualifying understanding for believing a proposition, and (b) that this case involves someone who lacks it. Now consider the following argument:

P1: If $\mathrm{S}$ believes $\mathrm{q}$, then $\mathrm{S}$ has a qualifying understanding of $\mathrm{q}$. P2: If $\mathrm{S}$ understands q to be a contradiction, then $\mathrm{S}$ takes q to be false. P3: If S takes q to be false, then, necessarily, S doesn't believe q. P4. If $\mathrm{S}$ has a qualifying understanding of ( $\mathrm{p} \& \sim \mathrm{p}$ ), $\mathrm{S}$ understands it to be a contradiction Therefore: 
C: $\mathrm{S}$ cannot believe $\mathrm{p} \& \sim \mathrm{p}^{7}$

We now have an argument for (ii) above. Do we also have a rationale for denying the possibility of someone's holding both the belief that $p$ and also the belief that $\sim p$, i.e., for moving from (ii) to (iii)? No. Since the contradiction is contained in a conjunction, there can be no question of whether the subject's stances on the conjoined propositions are, as I will put it, in mind or in consciousness together. Consider the absent-minded professor, who is preparing a sack lunch for her children, placing folders and books in their bags when she receives a text-message announcing that school has been cancelled for the day due to classrooms having been flooded by the recent rains. She is briefly overwhelmed by frustration over being deprived of another day of writing and broods over how frequently the school seems to shut down for one reason or another-all the while continuing to ready her children's things for a day at school. To make sense of the latter, we need to understand her as believing that her children are going to school; to make sense of the former, we need to understand her as believing that her children are not going to school. She holds contradictory beliefs.

${ }_{7}$ Some will object to the idea that $\mathrm{p} \& \sim \mathrm{p}$ is so much as a judgeable content. They may be right to do so. But my goal in this section is to persuade a philosopher who allows that someone might actually believe this (putative) content to disallow it. These reflections, if pursued beyond what's included in this essay, will perhaps culminate in the objector's position. Those who already occupy it can view the assumption that $\mathrm{p} \&$ $\sim \mathrm{p}$ is a judgeable content as a ladder ultimately to be thrown away. 
It is a crucial feature of the intelligibility of the absent-minded professor that her mind is in the relevant sense absent in relation to the behavior that grounds our ascription of one but not the other of the incompatible beliefs. This absence partly constitutes the lack of togetherness of the two stances. In this case it is a matter of distraction; in other cases, one or a combination of a variety of factors might explain it: denial, repression, forgetfulness, serious mental illness, etc.

It is important not to lose sight of the possibility of inconsistency or else we fall victim to an over-rationalization of the mind. But it is equally important not to lose sight of the fact that our beliefs paradigmatically do exhibit the togetherness that makes it impossible to hold contradictory beliefs. This point is tricky to formulate, as there is no way of doing so while remaining neutral about the nature of belief. The point is not, for example, that it would be impossible to possess the dispositions associated with both a belief and its contradictory. What is at issue is a person-level, categorical state. What the subject cannot do is at once 'view as true'-but not in the manner of a mere supposition-a proposition and its negation. The selection of a term here-belief, affirmation, judgment, acceptance-is fraught as they have all been worked over extensively in the literature. To refer to this categorical state I will continue to speak of beliefs as being in mind or in consciousness, expressions whose meaning I peg to the phenomenon in question: the impossibility of having the belief in mind while also having the belief in the negation of that very proposition in mind.

This categorical phenomenon cannot, I should also emphasize, be understood as corresponding to any episodes of inner speech-it is perfectly possible to silently utter a contradiction. Nor is there any reason to think it is reducible to a purely phenomenal state. My belief that my name is Eric is, in the foregoing sense, in mind when it does not 
even register as a presence in phenomenal consciousness. It would be impossible, after all, for me to acquire the belief that my name is not Eric without changing my mind. To say that a belief is in mind, in this sense, is thus not to say that it is 'occurrent'. It is just to say that my cognitive hold on the corresponding fact (or putative fact) is such as to exclude belief in its contradictory. Ultimately, more will have to be said about this. For the purpose of my argument here, I will treat the impossibility-phenomenon as definitive of the relevant sense of having a belief in mind or in consciousness, and so of multiple beliefs' being in mind or consciousness together.

I hope now to have drawn your attention to the fact that there is a mode of believing such that it is impossible to hold a pair of beliefs $\{\mathrm{p}, \sim \mathrm{p}\}$ in this mode. This is the substantive element of what would otherwise be a trivial consequence of my definition: that it is impossible to hold a certain combination of beliefs in mind. We are familiar with a manner of believing such that our own understanding of a pair propositions prevents us from believing both: an impossibility that is grounded in our own rationality. What explains why I cannot believe both that $\mathrm{p}$ and that $\sim \mathrm{p}$ (when I can't) is simply that I possess an understanding (unclouded by distraction, repression, etc) that it is impossible for both propositions to be true. ${ }^{8}$ We thus see how (i) helps to explain what is right in both (ii) and (iii).

8 The Preface Paradox might seem to be a counterexample to my claim that it is impossible to hold contradictory beliefs together in mind. S believes each of the propositions in her book but also, we can coherently suppose, that their conjunction is false. It should be emphasized, first, that the fact that this is called a paradox indirectly supports my contention that we are baffled by the idea of a clear-eyed embrace of 
We are also now in a position to dispel the appearance of a regress. It is impossible to believe an explicit contradiction because to understand a statement of the form ( $\mathrm{p}$ and $\sim \mathrm{p}$ ) is to know that it must be false. It follows that this understanding includes the belief that $\sim(p$ and $\sim p)$. Indeed, it would seem to be part of what it is to understand any proposition that its truth excludes the truth of its negation. If we found ourselves in conversation with one who apparently refused to abide by this rule, we would take this apparent refusal as a philosophical stunt or a joke or a bit of theatre. To know that a specific contradiction of the form ( $p$ and $\sim p$ ) cannot be true requires only the unimpeded exercise of the ability to make any judgment whatsoever.

The regress concerns the possibility of rationally rejecting a proposition because it is logically incompatible with something one already believes. Recall how it gets started. In order rationally to reject as logically inconsistent the combination $\{\mathrm{p}, \sim \mathrm{p}\}$ one needs to appreciate that $\sim(\mathrm{p}$ and $\sim \mathrm{p})$. And if the rejection of the former on the basis of the latter is to be rational (so not blind) it must be done with the appreciation that the set $\{\mathrm{p}, \sim \mathrm{p}, \sim(\mathrm{p}$ and $\sim \mathrm{p})\}$ is also inconsistent. Therefore, one must be aware that the conjunction of those propositions is necessarily false, and so forth. It thus seems as if we could never appreciate enough to reject the original combination non-blindly. But

contradiction. Second, note that S's belief that there is a false claim in her book has nothing in particular to do with it being her book; she believes that every substantial non-fiction book must contain at least one false claim, and that hers is one such book. This speaks to the disconnectedness of her preface-belief from the beliefs expressed in her book. I thus do not think it is ad hock to deny that the preface belief is in mind together with those made in the book itself. 
our discussion of simple contradictions shows that a belief that a certain combination of propositions is logically incompatible is part of a qualifying understanding of the original propositions. Thus, there is no regress-or, in any case, no vicious regress. The first-level appreciation already includes all of the appreciations necessary to rationally reject the contradictory proposition.

Does my solution attribute too many beliefs to a subject? No: it's not as if each of these beliefs must be flitting through the consciousness of a subject who rejects one belief on the basis of its incompatibility with another. Or that each such belief be represented individually in the brain. (Think, by way of comparison, of the beliefs I must hold in order to believe that $5>1$, viz., $6>1$, that $7>1$, etc.) Clearly, more would need to be said to flesh this idea out. The argument to follow shows, at the very least, how the idea can help us resolve the problem of inference.

There are, I contend, conditions under which it is impossible to hold contradictory beliefs. What explains this? Not that they would be a combination of entities that, by virtue of some metaphysically ineluctable force, invariably repel one another. Rather it is because under these conditions one would have to see that the propositions could not both be true. And to see-that is, to understand-that they cannot both be true is for the possession of one belief to exclude the possession of the other. Our beliefs are characterized by a mode of togetherness whose exclusion of contradictories in paradigmatic instances is a function of our understanding of the impossibility of their joint truth. 9

9 It is worth noting what's optional in my presentation of this line of thought. I assume here (and believe everywhere) that knowledge of the law of non-contradiction is part of 


\section{What I Must Believe}

Both Carroll's regress and the incompatible-variation concern how a combination of individual beliefs can, without the help of an additional belief, lead a subject directly to a certain doxastic result, and in doing so manifest the subject's rationality. The difference between Carroll's paradox and my variation is that the former concerns belief-acceptance, whereas the latter concerns belief-rejection. But the general strategy for resolving the variation can be extended to the original as well. The core idea is that an understanding of one's premises can by itself fully account for a one's ability to draw a conclusion because it is justified by those premises.10

what it is to be able to grasp any proposition whatsoever. However, the essential point is just this: in rejecting a proposition because it is incompatible with another (in whose truth one is convinced), one needn't bring to bear a separate, further judgment that the propositions are incompatible. Rather, there is something in our grasp of the very propositions themselves that equips us to rule out such a combination in virtue of their incompatibility. Believing a proposition must therefore involve the idea of propositional incompatibility.

${ }^{10}$ Something very much like this strategy for avoiding regress is considered and rejected by Barry Stroud in his 1979. Stroud rejects this strategy on the grounds that no specific belief can ever be a necessary qualification for possessing a concept. As I make plain here, I think he is wrong to do so. 
Consider a pair of premises that obviously entails a conclusion, premises that have the form (i) $p \rightarrow q$ and (ii) $p$. It is, I submit, part of a qualifying understanding of a conditional that its truth, together with the truth of its antecedent guarantees the truth of its consequent. Someone who does not know this does not possess the concept of a conditional, and so cannot believe a conditional proposition. And someone who believes a conditional knows this without the need for any additional beliefs. Thus, a secondlevel appreciation is already present in the subject's grasp of the premise-beliefs.

In the previous section, I introduced the idea of a belief's being in mind. It is for that belief to be such that I cannot come to hold the contradictory belief without a change of mind. I have no argument that there is a mode of belief such that it is impossible to hold a belief and its negation in mind together-that is a datum I'm simply counting on the reader to recognize. Similarly, I take the following to be a familiar phenomenon: one has in mind the beliefs that $\mathrm{p}$ and that $\mathrm{p} \rightarrow \mathrm{q}$, and so it is impossible not to believe q. There are circumstances in which beliefs of this form possess mental togetherness-there is no inattention, repression, etc. that would explain the failure to draw the conclusion-and so the subject is compelled by her own understanding to accept a conclusion that she recognizes as following logically from the premises that accepts. Under these circumstances-absent the relinquishing of a premise-it is impossible for her not to believe the conclusion. ${ }^{11}$ We can make the point from the

${ }^{11}$ There is, to be sure, a limit to how much one can hold together in one's mind at once. A series of inferences that relied on conclusions reached at earlier stages to establish the conclusions at later stages would eventually yield too many beliefs to hold together in consciousness. My argument here does not require us to explore the limits of the 
third-person perspective: the only way to make it intelligible that someone believes a conditional and its antecedent yet fails to draw the conclusion is to think that either he has failed to put the (would-be) premises beliefs together or has abandoned belief in one of them.

Since possession of the concept of entailment includes the knowledge that if $\mathrm{p}$ entails $q$, then the truth of $p$ guarantees the truth of $q$, the belief that ( $p$ and $p \rightarrow q$ ) $\rightarrow q$ is already part of what it is to believe the premises $\{\mathrm{p}, \mathrm{p} \rightarrow \mathrm{q}\}$. The belief that ( $\mathrm{p}$ and $p \rightarrow q) \rightarrow q$ is an element of the conceptual understanding operative in the subject's believing those premises. Thus, an inference by modus ponens satisfies the Taking Condition without regress. The thinker believes the conclusion because she must believe it, given what she already accepts as true. Her believing it is explained by her understanding of the support the premises lend to the conclusion. It is this understanding alone that makes it impossible (while the premise-beliefs are in mind) not to accept the conclusion.

The difference between the resolution of Carroll's paradox and my variation is that the former involves 'positive' as opposed to merely 'negative' necessity: something new must be believed. But there is nothing in the very idea that leads to regress. The contrary suspicion might arise from a supposed requirement that the acquisition of a new belief by inference must manifest itself in phenomenal consciousness. This strikes me as dubious. But even if it must explicitly occur to one, this would not lead to a

relevant capacity, though it is important to see that the very idea that there is such a limit does not undermine my argument here. Thanks to Sinan Dogramaci for drawing my attention to this issue. 
vicious regress. For it would not follow that all of the beliefs required to characterize the qualifying understanding would have to make an appearance in phenomenal consciousness. Nor would there have to be an individual act corresponding to each of these infinitely many beliefs. There is simply the appreciation, upon the premise beliefs being in mind together, that the conclusion must be true given the truth of the premises.

My discussion in this section has revolved around an example of reasoning that uses modus ponens. ${ }^{12}$ But, as I will stress in the conclusion, the basic idea can be fruitfully expanded to cover other kinds of reasoning. My focus here has been to establish the plausibility, in a very simple case, of an approach to understanding inference that avoids Carroll's regress. There is, however, aside from the fear of regress, another significant obstacle to my approach to 'taking'. It is the topic of the next section.

\section{Rational Causation}

${ }^{12}$ As in the case of the discussion in the previous section (see note 8), it is possible to shed some of the assumptions in this presentation of my central line of thought. The crucial point does not depend on modus ponens, but only on this: in accepting a proposition because it follows from others (in whose truth one is convinced), one needn't bring to bear a separate, further judgment that latter entail the former. Rather, there is something in our grasp of the very propositions themselves that equips us to accept the former in virtue of its following from the latter. Believing a proposition must therefore involve the idea of propositional entailment. 
I have been focusing on solving the problem of regress. I take overcoming it to be the key to understanding inference, and not simply one of many challenges for a comprehensive understanding of the phenomenon. It is central in virtue of its connection to the Taking Condition which, recall, runs as follows:

(Taking Condition): Inferring necessarily involves the thinker taking his premises to support his conclusion and drawing his conclusion because of that fact

The Taking Condition highlights two elements of inference. First, in inferring $\mathrm{p}$ from q, one draws a conclusion. The subject does something that marks a transition to believing that $\mathrm{p}$ (putting aside for rhetorical simplicity cases in which inference bolsters already existing beliefs). It is thereby brought about that the subject believes that $\mathrm{p}$. This bringing-about suggests causation in the broadest sense. Second, in inferring $\mathrm{p}$ from q, this bringing-about happens in light of the subject's endorsing the thought: $q$ supports p. Inference thus joins two elements: one causal, the other evaluative. But saying precisely how they are joined is tricky. There is a tendency to emphasize one element at the expense of the other, or to separate them in a fashion that renders them impossible to put back together again.

Here's a bold claim: A theory of inference that respects the Taking Condition must ultimately show that what appear to be the separate elements of inference are in fact not separate at all. Inference is the endorsement of a thought that the ground supports the grounded, and this endorsement must in some sense amount to a causal connection between the corresponding beliefs. It is the difficulty of seeing how this is possible that accounts for the seeming intractability of the problem. A complete account 
of inference must explain how it is possible that a mental act does not merely register the presence of a certain causal connection but constitutes there being such a connection.

Why do I say that an account of the Taking Condition must show that and how the evaluative and causal elements are inseparable? In a nutshell, it's because so long as they are separable, the account will be vulnerable to an intractable version of the "caused in the right way' objection. "But doesn't everyone have a 'caused in the right way' problem?” No. This particular problem is a consequence of a dispensable assumption about the relation between evaluative and causal elements of taking. Here, in capsule form, is an argument to that effect.

No one holds that an inference consists in the causal connection between premise and conclusion beliefs. After all, this transition might be a mere association of thoughts. But it must also be conceded that it does not help to add as an additional cause the extra belief that the premises support the conclusion. For the transition might still be mere association. Recently, the hope has arisen that the right way can be secured by requiring that the causation occur in virtue of the rationalizing relation between premises and conclusion. ${ }^{13}$ But this won't help either. After all, it might be that a demon zaps the subject into believing just what certain of her beliefs necessitate-and so zaps her precisely in virtue of their necessitating that conclusion-without the subject herself having inferred anything. ${ }^{14}$ And even if the specification is added that the transition between premise- and conclusion-beliefs manifests the subject's disposition (and not the

13 Arpaly and Schroeder 2013.

14 Their response to this objection is, I argue in Marcus, ms., ch. 4, inadequate. 
demon's) to infer what her current beliefs support, and to do so because of the support that those beliefs in fact lend to the relevant conclusions, it still will not help. ${ }^{15}$ For it matters why the subject has the relevant disposition, i.e., why she is so disposed. The demon might have altered me so that I am disposed to form beliefs according to the disposition just described, but where the disposition is not connected to my own evaluation of the support that the 'premise' beliefs lend the 'conclusion' belief. Perhaps I have no view at all about their connection or even honestly disavow any belief in their connection. In that case, there is still no inference.

To fully defend these arguments would require a paper of its own. ${ }^{16}$ It would be a paper that you've read many times before. My hope is that this synopsis will if nothing else convey how the general problem with attempts to specify the right way for a rationalizing cause to bring about its effect applies in this particular circumstance.

These attempted solutions envision various ways of configuring two ingredients, evaluation and causation, all the while holding fast to the idea that one might have the evaluation without the causation or the causation without the evaluation. But the solution to the problem of inference depends on seeing that the evaluation cannot be understood apart from its being an act that brings about a certain effect and the causation is of a sort that cannot be understood apart from its being constituted by a certain evaluation. Invoking the possibility of demonic interference is just a way to show that in separating the evaluation from the causation, it cannot be ensured that the subject's arrival at the conclusion-belief is accomplished under her own cognitive steam.

\footnotetext{
15 See Winters 1983, Wedgewood 2007, and Mantel 2017.

${ }^{16}$ I expand on this sketch in Marcus ms, chapter 4.
} 
And that is why I say that an account of the Taking Condition must reveal how taking the premises to support the conclusion can all by itself constitute the acquisition of the conclusion-belief. It is in trying to understand this possibility that we are confronted with Carroll's regress.

The regress arises precisely insofar as we suppose that taking the premises to support the conclusion is separate from drawing the conclusion. On our supposition there is more to adopting the conclusion then the taking. What can the missing element be? It had better be something that can be understood as attributable to the subject herself, or else the Taking Condition is simply surrendered. That is, if the extra element is just something that happens to the subject, then she herself will not have made an inference. We are conceiving, it would seem, of a subject who believes certain premises and also takes them to require a conclusion, but for whom there is still a question about whether to adopt the conclusion. This is precisely the position of the tortoise-at least as the tortoise describes it to Achilles. And Achilles discovers that the extra elementthat is, the element that when added to the original premises and the taking is supposed to ensure via logic that the subject possesses the conclusion-belief-cannot itself be an additional belief. For the assumption of the separateness of taking and drawing the conclusion will prevent the addition of the new belief from accomplishing what the addition of the taking couldn't accomplish to begin with. Instead, we should say that the taking can be part of one's understanding of the premises in their relation to the conclusion-proposition, and the adoption of the conclusion is in such cases nothing over 
and above this. ${ }^{17}$ This transition from premise to conclusion belief exemplifies essentially rational causation. ${ }^{18}$

\section{Taking as Understanding (and not Intuition)}

We should, I argue, explain taking in terms of understanding, specifically the sort of understanding that confers on a subject the ability to adopt attitudes towards propositions-either the ability to adopt attitudes towards propositions in general or the ability to adopt attitudes towards propositions with specific contents. This is conceptual understanding, as it pertains to the ability to cognize propositions. ${ }^{19}$ We can, for the purposes of elucidating the notion, identify a specific concept $\mathrm{x}$ simply as the ability to think about xs, where the relevant ability might be a merely qualifying one or where it

${ }^{17}$ Another philosopher who (in effect) argues for the inseparability of taking and drawing the conclusion is Markos Valaris. See Valaris 2014 and Valaris 2017. Taking the premises to establish the conclusion, on his view, constitutes the belief in the conclusion. For Valaris, however, taking is something over and above believing, as opposed to paradigmatic believing. This spoils the response to the regress worry defended here. I compare our approaches at length in Marcus, ms. ${ }^{18}$ See Marcus 2012 and Neta (forthcoming).

19 It remains an open question, as far as my argument here is concerned, whether the relevant understanding is always a matter of our knowledge of analytic truths relating concepts, or a matter of our grasp of logical forms, or sometimes one and sometimes the other, or of something else besides. 
might involve the possession of an articulate and complete grasp of the contribution the concept of an $\mathrm{x}$ makes to the truth-conditions of the propositions in which it is a constituent or, more likely, something in between these extremes. Plainly, the topic of conceptual understanding merits a discussion of its own. Although this is not possible here, nothing I say about it in this essay is especially controversial or at odds with the manner in which we ordinarily conceive it.

It is worth comparing my proposal to another that has gained some currency, according to which taking should be explained in terms of intuition. Elijah Chudnoff characterizes intuitions as follows:

Intuition experiences possess presentational phenomenology; whenever you have an intuition experience representing that $\mathrm{p}$, there is some $\mathrm{q}$ $($ maybe $=p)$ such that - in the same experience-it intuitively seems to you that q, and you seem to be intuitively aware of the chunk of reality that makes q true..$^{20}$

Intuition is thus distinguished from belief, since one can believe that q (say, on the basis of testimony) despite not having the relevant "presentational phenomenology". ${ }^{21}$ One might quarrel with the very idea of intuition so understood, or with the thesis that every inference is accompanied by some such phenomenology. One might worry especially that this view inadvertently encourages skepticism about the Taking Condition. Many will view such skepticism as justified by their own inability to detect the relevant

${ }^{20}$ Chudnoff 2014,

${ }^{21}$ Chudnoff 2014. 
intuition whenever they make an inference. ${ }^{22}$ But I will put these worries aside here and focus on the role intuitions are supposed to play in explaining a crucial feature of inference.

The central role played by the notion of intuition in discussions of inference is to answer what I'll call

The Knowledge Question: What explains why someone who knows q and infers $\mathrm{p}$ from $\mathrm{q}$ thereby acquires or can acquire knowledge that $\mathrm{p}$ ?23

Chudnoff contends that intuitions answer the Knowledge Question, reasoning as follows:

Consider the following two arguments.

Argument A

(A1) Connie and Cyndi are a cone and a cylinder with the same base and height.

(A2) Therefore, Cyndi encloses a greater volume than Connie.

Argument B

${ }^{22}$ See, e.g., Richard, ms.

${ }_{23}^{23}$ Slightly reformulated from Chudnoff 2014. See also Tucker 2012 and Dogramaci 2013. 
(B1) Connie and Cyndi are a cone and a cylinder with the same base and height.

(B2) Therefore, Cyndi encloses three times the volume of Connie.

Imagine Smith. Smith doesn't have any particular mathematical expertise. But suppose he has justification for believing (A1)-someone tells him it is so, or he measures it himself, or whatever. From (A1) he infers (A2). Plausibly, he now also has justification for believing (A2). Suppose, on the other hand, he has justification for believing (B1)we're just relabeling (A1). From (B1) he infers (B2). Is it plausible in this case to say that he has justification for believing (B2)? I think not. Why? On the face of it, it is because he can intuit that (A2) follows from (A1), but he cannot intuit that (B2) follows from (B1).24

This seems right: The fact that Smith can 'see' (in some sense) that (A2) but not that (B2) follows from their common premise helps to explain why knowledge is transmitted in the case of the (A) argument, but not the (B) argument. This lends some plausibility to the idea that taking should be explained in terms of intuiting.

But the tale of Smith has another lesson. Can Smith make Inference B? It might seem as if he can, even if he doesn't see that the conclusion follows, so long as he takes it to follow in some non-seeing fashion. For example, suppose he believes that it follows because a mathematician friend has told him it does. In that case, Smith certainly can arrive at (B2). But is this the inference from (B1) to (B2)? No. As Ulf Hlobil has argued,

24 Chudnoff 2014. 
in this scenario Smith has not inferred (B2) from (B1) alone, but from (B1) and the premise stating that (B1) entails (B2)-let's call that (B3).25 Smith has no need for an additional such belief in the case of the (A) inference, since it does not require any mathematical expertise. Whereas Smith can see that (A2) follows solely from (A1), he cannot see that (B2) follows solely from (B1). (Even though he can see that (B2) follows from (B1) and (B3)). Thus he can make the (A) inference but not the (B) inference. So we also need an answer to

\section{The Enabling Question: Why must someone who infers p from q 'see'} that $\mathrm{p}$ follows from $\mathrm{q}$ ?

Any plausible answer to the Enabling Question must, one would think, appeal to the following sort of fact: (A1) incorporates an understanding of (A2), whereas (B1) does not incorporate an understanding of (B2). This is precisely what Chudnoff's framing of the example (“Smith doesn't have any particular mathematical expertise”) encourages us to imagine. Smith does not understand the relationship between cones and cylinders sufficiently well to see that Cyndi encloses three times the volume of Connie. However, anyone who possesses a qualifying understanding of the concepts of cone and cylinder can see for herself that Cyndi encloses a greater volume than Connie. It's clear, then, how the Understanding View (as we can call it) answers the Enabling Question. Someone who infers p from q must see that the one follows from the other because 'sees' here means understands. One who infers must understand the premises (or at least

25 Hlobil, forthcoming. 
take themselves to understand the premises) ${ }^{26}$ well enough to find it impossible not to believe the conclusion. The burden is on the Intuition View (as we can call it) to provide an equally satisfying answer-one that does not rely on understanding.

The Understanding View also answers the Knowledge Question. There is no mystery about why someone who possesses a qualifying understanding of the concepts of a cone and cylinder and knows that Connie and Cyndi are a cone and a cylinder with the same base and height "acquires or can acquire" knowledge that Connie is larger than Cyndi. And there is also no mystery about why greater geometrical understanding can make it possible to acquire knowledge from the B-inference without any additional premises. What knowledge is within the reach of different subjects is (or can be) directly explained by their different degrees of understanding of the relevant concepts. It is also worth noting that the Understanding View of takings does not put the knowledge-transmission of inference at the mercy of a tenable story regarding the epistemology of intuitions. How our reliance on intuition yields knowledge is-at least in comparison to the corresponding question about understanding-obscure.

The Intuition View also fares worse on the questions of what the 'right' sort of causation is and of how to avoid regress. The explanation of taking in terms of intuition leaves open the question of how one who infers arrives at the conclusion on the basis of

${ }^{26}$ When someone acquires knowledge by inference then their understanding of known premises makes it impossible not to believe the conclusion, which is thereby known. In bad cases, either the premises are not known or the 'understanding' is the mere illusion of understanding. 
the premises plus the intuition. All of the issues discussed in the previous section arise here. It's not enough that the relevant beliefs plus intuition cause the subject to accept the conclusion. What must be added to the beliefs and intuitions such that our subsequently believing the conclusion necessarily excludes causal deviance? Answering this question is, as we have seen, exceedingly challenging. Furthermore, whatever the mystery item is said to be, there will remain the question: Is it or is it not necessary for Smith to appreciate that the premises and the intuition together support the conclusion? If it is necessary, there then emerges the identical question about the higher level of appreciation. Regress looms. If it is not necessary, then Smith does not arrive at (B2) by inference.

Finally, the Understanding View works equally well in accounting for the inferential basing relation: that is, the relation that persists between beliefs so long as I believe one in virtue of its support by another. In characterizing inference thus far, I have mainly referred to a scenario in which a person acquires a belief on the basis of her understanding of the premises. But since understanding itself is not episodic, what explains why I (continue to) believe that Cyndy is larger than Connie can (still) be the fact that I understand Cyndy is a cylinder and Connie is a cone and that they have the same base and height. By contrast, a proponent of the Intuition View needs a different account to explain basing, since there is no plausibility at all to the claim that for every belief $\mathrm{p}$ I hold on the (inferential) basis of $\mathrm{q}$, I am constantly experiencing an intuition that q supports p.

\section{Conclusion}


I've tried to convey here, via a simplifying sketch, the plausibility of an approach to inference that I believe can be fruitfully expanded. By way of conclusion, I will indicate how. Our discussion of Chudnoff's example has already given us a start. We have begun to see how the Understanding view can be extended to accommodate inferential basing in addition to inference itself. Other issues raised by the example merit comment. Smith is able to infer (and so to gain knowledge) on the basis of the (A) inference not by using modus ponens, but simply by exploiting a qualifying understanding of the concepts of a cone and a cylinder (or it at least so it would seem). And someone with mathematical expertise can make the (B) inference-and make it without the need for the extra premise (B3) - on the basis of a more than merely qualifying understanding. This points to a way of extending the account of inference beyond modus ponens and also to more-than-merely-qualifying understandings. I'll briefly discuss these.

The core idea of this essay is that one infers when one becomes conscious of a necessity. The conclusion must be true, or so it seems from the point of view of the premises. The core idea does not determine an answer to the question of how precisely to understand the 'must': perhaps it is always a matter of logical form, as in our discussion of reasoning using modus ponens, or perhaps, as in the case of the (A) argument above, it is sometimes a matter material inferences that utilize a qualifying understanding of the relevant concepts. In making the (A) inference, Smith would seem to rely simply on the geometrical understanding that was operative in his premise belief. He does not (or does obviously) use modus ponens.

The (B) argument points to an extension beyond merely qualifying understandings. Let us return momentarily to the impossibility of believing a 
contradiction. Someone with a more-than-qualifying understanding of some concept that figures in my beliefs can spot an inconsistency that I've missed. For her, it would be impossible to hold that combination of beliefs. And while it's true that she holds a belief that I don't-viz., that that combination is inconsistent-this 'extra' belief is part of her superior understanding of the very concepts that figure in my beliefs. Thus, although she and I may share a belief-the holding of which draws into operation the very same concepts-she has a better grasp of the belief than I do. The analogous phenomenon manifests itself in the case of the mathematician who makes the (B) inference. Although we must, in order to see her as making the inference, attribute to her the belief (B3), this belief is-for her-already part of her understanding of the concepts that figure in (B1) and (B2). This is why we do not need to see her as inferring (B2) from anything over and above (B1) - notwithstanding her holding a belief that Smith lacks. She-unlike Smith who, recall, believes (B3) on the basis of testimony-can arrive at (B2) without using modus ponens. She-like Smith when he makes the A-inference-relies just on a geometrical understanding of the concepts that figure in the premise and conclusion. The fact that she and Smith share concepts ensures that it is the very same proposition (B1) that both believe. But to understand the mathematician's inference, we must see her hold on (B1) as such as to make it impossible (absent the relinquishing of this hold) for her not to draw the conclusion (B2). ${ }^{27}$

${ }_{27}$ Things get much trickier when it comes to non-deductive inferences. Here is a very brief pass at the issue. Following Harman, we might view induction as a combination of abduction and deduction. I know that the sun must rise next Tuesday; after all, it rises every day. So far this is deduction. Why do I believe the generic proposition? Because 
A fuller version of the account I've begun to sketch here will eliminate the artificial neatness of the in mind/out of mind distinction. Mental reality is, of course, more nuanced than that distinction suggests. A perfectly rational believer would have a full, active understanding of all of her beliefs, each of which would be a constituent of her ongoing self-conscious doxastic framework. But, in reality, our understanding of the propositions that we believe is a matter of degree, our minds are absent in relation to many of our beliefs, and the failure to put what we know together to draw a conclusion is common. Still it is useful to begin with a relatively crude distinction, so as to draw attention to the fact that there is an absolute limit to irrationality, to the fact that there are conditions under which one cannot or must adopt a further belief. Thus, the in mind/out of mind distinction, though artificially neat, helps us to resolve longstanding puzzles about inference, even if in the end it should give way to a messier understanding of the mind and our relation to it.

A final thought: Even supposing the account could be extended in the manner just indicated, a crucial question would remain unexplored. What precisely is it for a

it is the best explanation of the welter of evidence regarding how the solar system operates. (See Harman 1965.) Abductive inferences also involve a consciousness of necessity. From the point of view of the premises-the evidence-I conclude it must be true that the sun rises every day. In so arriving at this conclusion, I view as 'off the table' bizarre hypotheses consistent with the evidence and also the falsity of the conclusion. How precisely to understand what one might call abductive necessity is task for another occasion. 
pair of beliefs to exhibit mental togetherness? This is another way of asking: What makes a pair of beliefs part of a single view of the world as opposed to shards of separate views? What confers on a worldview the unity of being someone's? Why is a charge of inconsistency appropriate (when it is appropriate) as opposed to disagreement? This is another way of asking about the nature of the togetherness of beliefs in a single consciousness. Ultimately, the success of the Understanding View depends on answering these questions as well. ${ }^{28}$

\footnotetext{
${ }^{28}$ Versions of this paper were presented in the Humboldt Conversations in Philosophy series at the University of Leipzig in 2018, the 2018 Analytic Philosophy Symposium at the University of Texas at Austin, and the 2019 Normativity and Reasoning Workshop at NYU Abu Dhabi. Thanks to those audiences, to Matt Boyle, Chris Blake-Turner, James Conant, Sinan Dogramaci, Arata Hamawaki, Jonas Held, Christian Kietzmann, Irad Kimhi, Ram Neta, Gilly Nir, David Sosa and, especially, to Ulf Hlobil.
} 


\section{References}

Arpaly, Nomy \& Schroeder, Timothy (2013). In Praise of Desire. Oxford: Oxford University Press.

Boghossian, Paul (2003). Blind reasoning. Aristotelian Society Supplementary Volume 77 (1):225-248.

Boghossian, Paul (2014). What is inference? Philosophical Studies 169 (1):1-18.

Carroll, Lewis (1895). What the tortoise said to Achilles. Mind 4 (14):278-280.

Chudnoff, Elijah (2014). The Rational Roles of Intuition. In Anthony Booth \& Darrell Rowbottom (eds.), Intuitions. Oxford: Oxford University Press: 9-35.

Dogramaci, Sinan (2013). Intuitions for inferences. Philosophical Studies 165 (2):371399.

Harman, Gilbert H. (1965). The inference to the best explanation. Philosophical Review 74 (1):88-95.

Hlobil, Ulf. We Cannot Infer by Accepting Testimony. Philosophical Studies (forthcoming). 
Kimhi, Irad (2018). Thinking and Being. Cambridge, MA: Harvard University Press.

Mantel, Susanne (2017). Three Cheers for Dispositions: A Dispositional Approach to Acting for a Normative Reason. Erkenntnis 82 (3):561-582.

Marcus, Eric (2012). Rational Causation. Cambridge, MA: Harvard University Press.

Marcus, Eric (manuscript). Belief, Inference, and the Self-Conscious Mind.

Neta, Ram (forthcoming). "The Basing Relation". Forthcoming in the Philosophical Review.

Richard, Mark. Is Reasoning a Form of Agency?

Stroud, Barry (1979). Inference, belief, and understanding. Mind 88 (350):179-196.

Tucker, Chris (2012). Movin' on up: higher-level requirements and inferential justification. Philosophical Studies 157 (3):323-340.

Valaris, Markos (2014). Reasoning and Regress. Mind 123 (489):101-127.

Valaris, Markos (2017). What reasoning might be. Synthese 194 (6): 2007-2024. 
Wedgwood, Ralph (2007). Normativism defended. In Brian P. McLaughlin \& Jonathan D. Cohen (eds.), Contemporary Debates in Philosophy of Mind. Malden, MA: Blackwell. pp. $85^{--102 .}$

Winters, Barbara (1983). Inferring. Philosophical Studies 44 (2):201 - 220. 